will have a limited application and that these may be at the expense of the basic needs of the clinical continuity and proper communication and co-ordination of care. To be specific on but one point is to refer to the hazards of cross-cover especially at a junior level of experience, where the pressure on the doctor will be high.

These and other aspects of the situation referred to in your columns will continue to exercise every level of hospital staff in the coming months. In my district general hospital the senior medical staff committee which I represent as chairman has expressed considerable disquiet at the view expressed in the Department's communication. We shall seek to examine the advice given and to put it into effect, but where the only answer to increased leisure for some is increased work by others already committed, there is limited room for manœuvre.-I am, etc.,

D. STONE Visiting Medical Staff Committee Royal Berkshire Hospital, Reading

\section{Independence of Review Body}

SIR,-If any doubt still lingers in the minds of the profession as to the present position of the Review Body vis-à-vis the original remit of this Body as set out by the Royal Commission 1957-19601 these doubts should now be clearly dispelled by study of the contents of the letters from Sir Keith Joseph on the working of the present Review Body (Supplement, 17 November, p. 44, and 24 November, p. 52). The political urbanity of the letters is more striking than any considered judgement on the original remit of the Review Body. The action by Government to nullify the Review Body mechanism starting with the Prices and Incomes Board of the Wilson era of counterinflation policy, has now been completed by studied action from the Heath Government to make the present Review Body mechanism a complete facade in terms of its original remit.

The two most telling quotations from the original Royal Commission Report as a yardstick of present realities are: (1) "Doctors and dentists ... have a right to receive fair treatment and to know whether they are receiving it" (II.23). They "should not be used as a regulator of the national economy. Their earnings should not be prevented from rising because of a fear that others migh follow" (II.28). (2) "It [the Review Body] must be regarded as a better judge than either the Government or the representative of the professions as to what the levels and spread of medical and dental remuneration should be. While the Government cannot abrogate its functions and responsibility for ultimate decisions, we are insistent that the recommendations of the Review Body must only very rarely and for most obviously compelling reasons be rejected" (II. 13, 14) It is the term "compelling reasons," which has been used not rarely but repeatedly when modifying Review Body awards, which makes the Review Body position completely untenable in the face of the original remit.

Any Review Body award should, as originally intended, be based entirely on the relativities of level and spread of professiona incomes. To suggest, as did the Wilson Government and now the present Govern- ment, that any review should be predetermined by a Government-sponsored body such as the Prices and Incomes Board or Pay Board, is to prejudge the entire exercise. Either the Review Body makes its report unfettered by any such considerations and leaves the ensuing amendment to the Government or it must resign on the inability to fulfil its original remit.

The profession's representatives have ceded too many points on the operation of the Review Body and its original remit to restore the status quo. It is still not too late to throw out Sir Keith's suggestion that the Review Body should first satisfy itself that the requirements of the Pay Board should be met before consideration of the substance of any award. If this is not done the long-held view of the profession that the Review Body mechanism is now a farce will be strength ened to the point that a realistic alternative in pressing for remunerative justice must be sought.

Sir Keith's inevitable argument that it was the profession which destroyed the Review Body would convince few observer in the light of today's credibility gap. Hi letters contain a message clear for all to read-the Review Body mechanism is finished as a source of "fair treatment." It is now a millstone round the profession's neck. In composition and function it is only an expensive anachronism we can no longe afford if any reasonable incomes relativity is to be preserved with the industrial field.am, etc.,

Rainham, Kent

J. RUFFEL

1 Royal Commission on Doctors' and Dentists' Remuneration 1960 .

\section{Medical Immigration}

SIR,-The article by Dr. Myre Sim (Supplement, 8 December, p. 65) on this subject appears exactly five years after you published my letter calling for the introduction of the E.C.F.M.G. (Educational Council for Foreign Medical Graduates) examination in Britain (7 December 1968, p. 643). May I repeat one paragraph?

"Medical immigration has, of course, an important economic aspect. If we had not come to rely on the services of the thousands of doctors from abroad the Ministry of Health would have had to admit years ago that the country was short of doctors and would have been obliged to do something about it. The fact that it can count on an annual gain of overseas doctors enables the Ministry to make reassuring noises about medica manpower. It does nothing to strengthen the hand of our negotiators when they approach the Review Body."

Since these words were written we have ost another 2,000 British doctors to other countries. Better pay would have kept them here, but our politicians prefer cheap doctors to good doctors. Unlike Dr. Sim, they think that numbers are more important than standards. It is disgraceful that they have been supported in their cynical policy by a General Medical Council whose ostenible purpose is to maintain proper levels of medical competence. Britain is the only country in Europe that admits ill-trained foreign graduates. As a result, British doctors are the worst paid in Europe. 1 This situation will not improve until the G.M.C. carries out the functions for which it was set up in 1858. After all, why should the Government give doctors realistic pay while hey know that they can always get someone from somewhere to take the place of every departing British graduate?-I am, etc.,

JAMES N. DOChERTY Tower Hamlets Division, B.M.A.

London E.3 Inch, R, S., British Medical fournal, 1972, 3, 749 .

\section{Delayed Attacks of Malaria in Visitors} to the Tropics

SIR,-I have followed with interest the correspondence on this subject (22 September, p. 637, 20 October, p. 172, and 24 November, p. 493). I have seen many hundreds of delayed attacks of Plasmodium vivax malaria in Britain, in troops returning from Salonika in 1917-8 and in cases of malaria therapy between 1922 and 1960, as well as numerous cases in several countries in Eastern Europe.

It seems not to be fully appreciated that a delayed incubation period of 6-12 month is a biological feature of $P$. vivax malaria This long latent period occurs with many strains, not only those from temperate zones but also in a number from tropical zones such as the Cameroons, Ceylon, India, and Madagascar. ${ }^{2}$ From some of the correspondence the implication seems to be that latency of the primary attack has something to do with drug prophylaxis. With Dr. Paul Horstmann's (25 August, p. 440) cases in which he gave chloroquine for two weeks after the group returned to Denmark the result would have been the same had he given prophylactic drugs for 10,20 , or even 30 weeks.

Where the parasite of $P$. vivax rests and in what form it is over a period of severa months following infection and between the end of the primary attack and a long-term relapse is still not known. If, as many believe, the parasite is resting in the liver, why is it that the delayed incubation period in the majority of cases is around the 38week period? The first relapse in most cases of $P$. vivax infection following drug therapy of the primary attack corresponds exactly with the time factor of a prolonged incubation period of a primary infection-that is about 38 weeks.

In 1917-8 there were 500 cases of indigenous $P$. vivax malaria in Britain following the return of relapsing cases from Salonika. Over $50 \%$ of these patients, mostly children, developed fever during the months of April, May, and June. It is certain that all these patients were infected the previous autumn. In England the carrier species, the semi-hibernating Anophles labranchiae atroparvus, do not leave their winter quarters until late in April or early May. The temperature of the water in which this species breeds is so low that the first season's adults do not appear on the wing until June. If any adults from this first generation fed on a gametocyte carrier and became infected again because of the low atmospheric temperature the cycle of the parasite in the mosquito (sporozoites in the salivary glands) would take at least a month. Therefore any patients with primary infections of $P$. vivar occurring in Britain must have been bitten 
by an infected mosquito in the previous autumn.

In the great epidemic of malaria in Ceylon in 1934, in which both $P$. falciparum and $P$. vivax were involved, there was another wave of fever cases nine months later, but all were $P$. vivax infections. Based on our observations at Horton Hospital, the late Colonel S. P. James warned the Ceylon authorities to expect this wave and $\mathrm{Dr}$ Briercliffe wrote to Colonel James saying that had he, Colonel James, not given this warning he would have thought that another epidemic had begun.-I am, etc.,

P. G. SHUTE

Leatherhead, Surrey

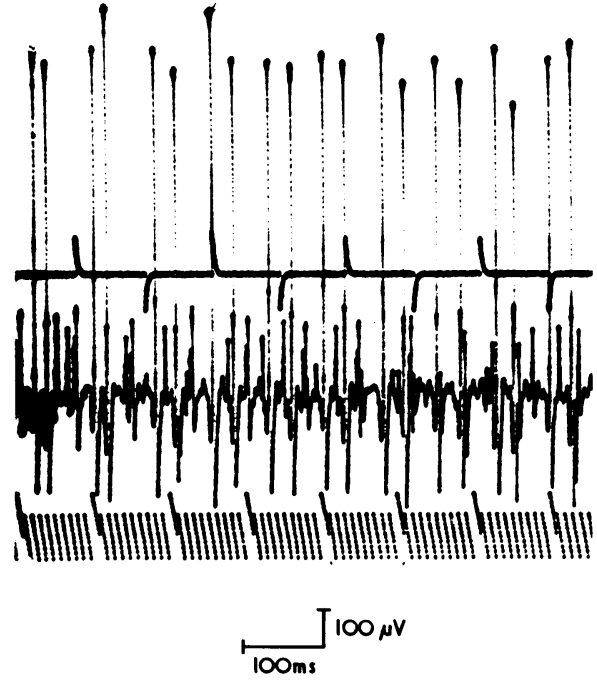

in the corresponding muscles and by the E.M.G. findings. The clinical picture was otherwise that of a myopathy. Polyradiculitis, polyneuritis, collagenosis, and metabolic disorders could be excluded. The patient did not drink alcohol and took no drugs except chloroquine. A daily dose of $300 \mathrm{mg}$ chloroquine base has been reported to increase the plasma drug concentration to a plateau of $20-40 \mu \mathrm{g} / 100 \mathrm{ml}$ after four weeks. ${ }^{6}$ A weekly dose of $316 \mathrm{mg}$ base produced plasma levels of $10-20 \mu \mathrm{g} / 100 \mathrm{ml}$ after six hours, decreasing to about $2 \mu \mathrm{g} / 100 \mathrm{ml} 42$ hours later.? Our patient's chloroquine levels after 300 $\mathrm{mg}$ base on two occasions at an interval of 54 hours are shown in the table. Her blood

Concentration of chloroquine in blood $(\mathrm{g} / 100 \mathrm{ml})$ after two separate oral doses of $300 \mathrm{mg}$ base

\begin{tabular}{c|c|c|c|c|c|c}
\hline \multirow{2}{*}{ Dose } & \multicolumn{3}{|c|}{ Hours after administration } \\
\cline { 2 - 7 } & 0 & 4 & 8 & 12 & 24 & 48 \\
\hline 1 & 10 & 80 & 55 & 45 & $15 ?$ & 50 \\
\hline 2 & & & & 60 & 80 & 50
\end{tabular}

levels were fairly high (up to $80 \mu \mathrm{g} / 100 \mathrm{ml}$ ) even considering that chloroquine concentration in the erythrocytes is up to twice that in plasma. This might indicate a tendency to accumulate chloroquine in spite of normal liver function. Together with her symptoms and signs this strongly suggests a chloroquine neuromyopathy.-We are, etc.,

ANITA KARSTORP HARRY FERNGREN PER LUNDBERGH

Roslagstulls Sjukhus

ULLA LYING-TUNELI

Södersjukhuset,

Stockholm, Sweden

1 Whisnant, J. P., et al., Proceedings of the Staff Meetings of the Mayo Clinic, 1963, 38, 501 .

2 British Medical fournal, 1964, 1, 452. fournal, $1964,1,770$. 7 , Armal de Médecine de
fureau, et., fournal de Nantes, 1965, 5, 107. Fournal de
(19) Weekly Epidemiological Record, 1973, 48, 25. Alving, A., et al., fournal of Clinical

McChesney, E. W., Banks, W. F., and McAuliff, J. P., Antibiotics and Chemotherapy, 1962, 12, drug in the blood tion on 9 February muscle strength had improved jerks were still absent. She returned to Kenya at her own request and was prescribed $50 \mathrm{mg}$ pyrimethamine weekly for suppression. In May 1973 normal muscle strength and knee jerks were reported.

This case of neuromyopathy is in good accordance with those earlier reported. A neurogenic component was indicated by absent jerks with moderate or no weakness by, - I was most interested in the paper malm (1 Din Enzell and Gunnar since Dr. J. MacD. Holmes and I first wrote about episodes of cerebral arterial insufficiency in the users of oral contraceptives ${ }^{1}$ I have become increasingly convinced that embolism was a more common cause for proven arterial occlusions than thrombosis at that site, and that the passage of emboli might acount for many of the more transient episodes. This is not based so much on the clinical presentation the authors quote, for this can be a very unreliable way of diagnosing embolism, but from the arteriographic appearances, which resemble those in other known causes of embolism, and from the normal state of the arterial wall repeatedly shown radiologically and also from records of necropsies, including one of our own series involving the vertebrobasilar system. ${ }^{2}$ This applies at the site of the occlusion and elsewhere.

What then is the origin of such an embolus? In an experience of over 60 examples of cerebral ischaemic episodes in young women on the pill I had been very impressed that only one case had occurred in a nullipara. The present authors' series does not support this, but I had hypothesized that in a previous pregnancy a reservoir of venous thrombi might have formed in the legs or pelvis and that for reasons unknown, and by pa hways unknown, had been mobilized and gained access to the arterial side of the cerebral circulation. This was the crux of the problem because patent cardiac septal defects could account for only very few. Drs. Enzell and Lindemalm suggest an alternative reservoir in the pulmonary vascular bed. This is an attractive idea because it would solve many of the difficulties, and I hope that any necropsy studies that may have been, or will yet be, carried out will pay special attention to this possibility. The fact of an association between the pill and episodes of arterial cerebral insufficiency is now widely accepted-the explanation of that fact still eludes us.-I am, etc.,

EDWIN R. BICKERSTAFF

Birmingham

1 Bickerstaff, E. R., and Holmes, J. MacD., British Medical fournal, 1967, 1, 726.

Ehtishamuddin, M., British Medical fournal, 1965 1, 921 .

\section{Oral Contraceptives and Myocardial} Infarction

SIR,-Dr. G. Lloyd suggests in his letter (20 October, p. 167) that three patients in our series of young women who had myocardial infarction while using oral contraceptives (25 August, p. 428) may have been taking this form of contraception because they were already hypertensive and unable to accept other methods of birth control.

This is not so. Of the three women documented as being hypertensive, one had normal blood pressure readings during pregnancies in 1959, 1962, and 1964. She was then started on oral contraceptives, on the recommendation of a gynaecologist, for symptoms of menorrhagia, premenstrual tension, and backache. Her records subsequently showed elevated diastolic pressure readings in 1971 and her name was placed on the waiting list for a hysterectomy in February 1972, but before she was called for operation she had a myocardial infarction in May 1972. Another woman had been taking oral contraceptives for eight years. She was 